\title{
Genetic structures across a biogeographical barrier reflect dispersal potential of four Southeast Asian mangrove plant species
}

\begin{abstract}
Aim: Biogeographical barriers restrict the movement of individuals, resulting in population divergence, genetic differentiation, endemism and speciation. Yet, some barriers demonstrate unequal effect across species depending on species dispersal, which manifests in varying genetic structure. We test the hypotheses that the genetic structure of four coastal mangrove species would reflect differences in dispersal potential across the Malay Peninsula, a major biogeographical barrier in the Indo-West Pacific region. Location: East and west coasts of the Malay Peninsula. Taxon Mangrove trees Avicennia alba, Sonneratia alba, Bruguiera gymnorhiza and Rhizophora mucronata. Methods: For each species, we characterized genetic structure and gene flow using $7-$ 12 species-specific nuclear microsatellite markers. We tested for east-west genetic differentiation across the peninsula, a stepping-stone migration pattern, and assessed the proportion of recent dispersal and direction of historical migration along the Malacca Strait. Results: Significant eastwest genetic differentiation across the peninsula was observed in A. alba, S. alba and B. gymnorhiza, and the effect was most pronounced for the two species with lower dispersal potential (A. alba, S. alba). In contrast, the two species with higher dispersal potential (B. gymnorhiza and R. mucronata) exhibited much higher proportion of recent inter-population migration along the Malacca Strait. The signature of historical colonization from refugia in the Andaman Sea (northto-south migration along the Malacca Strait) predominated for A. alba and S. alba. Historical south-north migration predominated for R. mucronata and B. gymnorhiza. Main conclusions: This study implicated dispersal potential as a cause of varying mangrove species genetic structure across a biogeographical barrier. The Malay Peninsula functions as a filter to gene flow rather than a barrier. The genetic structure in mangrove species with a higher dispersal potential is more congruent with contemporary gene flow while that of species with a lower dispersal potential reflects historical processes. Our findings hint at the role of dispersal potential as a predictor of gene flow in mangroves.
\end{abstract}

